\title{
O ENSINO DO VALOR DO DINHEIRO NO TEMPO POR MEIO DE ATIVIDADES
}

\author{
TEACHING THE VALUE OF MONEY OVER TIME THROUGH ACTIVITIES
}

ENSEÑAR EL VALOR DEL DINERO A LO LARGO DEL TIEMPO A TRAVÉS DE ACTIVIDADES

\section{André Alves Sobreira (iD) 9 \\ Mestre em Ensino de Matemática (UEPA) \\ Docente da Secretaria Executiva de Educação do Estado do Pará (SEDUC - PA) e da Secretaria Municipal de Educação de Ipixuna do Pará andreuepa@yahoo.com.br}

\section{Ducival Carvalho Pereira (iD) 9}

Doutor em Matemática (UFRJ) Docente do Programa de Mestrado Profissional em Ensino de Matemática da UEPA ducival@uepa.br

\section{Pedro Franco de Sá}

\section{(iD) 9}

Doutor em Educação (UFRN)

Docente do Programa de Pósgraduação em Educação e do Mestrado Profissional em Ensino de Matemática da UEPA e Docente da REAMEC pedro.sa@uepa.br

\begin{abstract}
Resumo
Este trabalho apresenta os resultados de uma pesquisa que teve como objetivo analisar informações pertinentes aos resultados da aplicação de uma atividade para trabalhar a noção de valor do dinheiro no tempo. Participaram da parte experimental 21 estudantes do $3^{\circ}$ ano do ensino médio de uma escola pública, localizada em Aurora do Pará. A análise das questões resolvidas pelos estudantes, bem como as conclusões apresentadas, no momento dos registros, nos revelou que os mesmos, após a atividade, demonstraram entendimento do conceito do valor do dinheiro no tempo. O experimento didático nos permitiu perceber o quanto é importante que possamos trabalhar com metodologias diferenciadas nas aulas de Matemática, uma vez que assim, os estudantes conseguiram assimilar os conceitos apresentados.
\end{abstract}

Palavras-chave: Ensino de Matemática. Matemática Financeira. Valor do Dinheiro no Tempo.

Recebido em: 26 de junho de 2020.

Aprovado em: 11 de dezembro de 2020.

Como citar esse artigo (ABNT):

SOBREIRA, André Alves; PEREIRA, Ducival Carvalho; SÁ, Pedro Franco de. O ensino do valor do dinheiro no tempo por meio de atividades. Revista Prática Docente, v. 6, n. 1, e002, 2021. 


\section{Abstract}

This paper presents the results of a survey that aimed to analyze information relevant to the results of applying an activity to work the notion of value of money in time. They participated in the experimental part 21 students of the $3^{\text {rd }}$ year of the high school of a public school, located in Aurora do Pará. The analysis of the issues resolved by the students, as well as the conclusions presented at the time of registration, revealed that they, after activity, demonstrated an understanding of the concept of the value of money over time. The didactic experiment allowed us to realize how important it is that we can work with different methodologies in Mathematics classes, since in this way, students were able to assimilate the concepts presented.

Keywords: Mathematics Teaching. Financial Math. Value of the Money in Time.

\section{Resumen}

Este trabajo presenta los resultados de una investigación que tuvo como objetivo analizar información relevante a los resultados de la aplicación de una actividad para trabajar la noción del valor del dinero en el tiempo. En la parte experimental participaron veintiún estudiantes del $3^{\circ}$ año de una escuela pública, ubicada en Aurora do Pará. El análisis de las cuestiones resueltas por los estudiantes, así como las conclusiones presentadas al momento de la inscripción, revelaron que, luego de actividad, demostró comprensión del concepto del valor del dinero a lo largo del tiempo. El experimento didáctico nos permitió darnos cuenta de lo importante que es que podamos trabajar con diferentes metodologías en las clases de Matemáticas, ya que de esa manera, los estudiantes pudieron asimilar los conceptos presentados.

Palabras clave: Enseñanza de las Matemáticas. Matemática Financiera. Valor Temporal del Dinero. 


\section{INTRODUÇÃ̃O}

Os conhecimentos de Matemática encontram-se bastante presentes na vida do ser humano, auxiliando-o nos estudos em outras ciências e também para que, de forma mais simplificada, o mesmo possa lançar mão de ferramentas para resolver problemas. A parte de tal disciplina que faz menção aos problemas financeiros, os quais encontram-se bem presentes na vida de todas as pessoas, sem dúvidas, tem extrema importância, ainda mais em nosso país, em que, devido às condições sociais, temos uma desigualdade social enorme, que implica, consequentemente, em pessoas endividadas, entre outras coisas semelhantes.

Muitas desigualdades e questões de endividamentos, por exemplo, resultam de falta de informações por parte das pessoas e, por este motivo, os Parâmetros Curriculares Nacionais (PCN) destacam que "o currículo do Ensino Médio deve garantir [...] espaço para que os alunos possam estender e [...] a Matemática na interpretação e intervenção no real” (BRASIL, 2000, p. 44). Além do mais, a educação deve ter um papel de formar pessoas prontas para que, em múltiplas situações do cotidiano, possam ser capazes de realizar tais tarefas, que são, na verdade bastante desafiadoras e que necessitam de organização do pensamento crítico, fato que pode ser atingido pelo ensino da Matemática (BRASIL, 1999).

As Diretrizes Curriculares Nacionais para o Ensino Médio (DCNEM), documento que tem a função de organizar e articular as diversas propostas pedagógicas para o segmento educacional em questão, no Brasil, tanto na rede pública como privada, destacam que

Tendo em vista que a função precípua da educação, de um modo geral, e do Ensino Médio - última etapa da Educação Básica - em particular, vai além da formação profissional, e atinge a construção da cidadania, é preciso oferecer aos nossos jovens novas perspectivas culturais para que possam expandir seus horizontes e dotá-los de autonomia intelectual, assegurando-lhes o acesso ao conhecimento historicamente acumulado e à produção coletiva de novos conhecimentos, sem perder de vista que a educação também é, em grande medida, uma chave para o exercício dos demais direitos sociais (BRASIL, 2013, p. 147).

Além do mais, podemos, de modo especial explicitar alguns pontos importantes com relação à educação básica brasileira, destacados na Base Nacional Comum Curricular (BNCC) que apresenta, para os estudantes do ensino médio, a necessidade que os mesmos, ao final da educação básica tenham desenvolvido capacidade de

Argumentar com base em fatos, dados e informações confiáveis, para formular, negociar e defender ideias, pontos de vista e decisões comuns que respeitem e promovam os direitos humanos, a consciência socioambiental e o consumo responsável em âmbito local, regional e global, com posicionamento ético em relação ao cuidado de si mesmo, dos outros e do planeta (BRASIL, 2017, p. 19, grifo nosso). 
Nessas condições, sem dúvidas, a escola deve buscar mecanismos para que os estudantes consigam atingir as habilidades esperadas dos mesmos ao fim da etapa educacional em questão, formando pessoas que sejam, baseadas em critérios científicos, críticas e que possam, dessa maneira, compreender os múltiplos fenômenos, entre os quais podemos destacar e dizer que merece bastante atenção, os debates referentes a temas financeiros, que comumente ocorrem ao nosso redor. Acreditamos assim que, por tal fato a BNCC, com relação a Matemática, apresenta para o Ensino Médio, cinco competências básicas, das quais em quatro delas destacamse habilidades relativas ao estudo de fatos pertinentes à Matemática Financeira (BRASIL, 2017).

Desta maneira podemos destacar que, através do estudo da Matemática Financeira, que subdivide-se em diversos temas, entre eles o valor do dinheiro em função do tempo, tem-se a oportunidade de que algumas reflexões bem presentes em nosso cotidiano sejam realizadas, uma delas, por exemplo, é o entendimento de que o dinheiro tem seu valor de acordo com o tempo.

Sendo assim, entendemos que, no âmbito escolar, buscando novas formas de ensinar e aprender, os atores envolvidos no processo de aprendizagem devem apresentar situações que venham a propiciar situações em que os estudantes aprendam sobre o valor do dinheiro ao longo do tempo.

Outrossim, destacamos que a temática é bastante importante, pois ajudará, em diversos momentos da vida, para que uma pessoa decida se a melhor opção é uma compra à vista ou em parcelas. Além disso, conhecer o valor do dinheiro no tempo ajuda para que entendamos o custo de oportunidade que o mesmo propicia, ou seja, numa situação de compra, sem o conhecimento mencionado, o cidadão deixa de pedir um desconto e assim, perde dinheiro.

Este artigo apresenta os resultados da análise da aplicação de uma atividade para trabalhar a noção do valor do dinheiro no tempo.

\section{REFERENCIAL TEÓRICO}

A seguir explicitaremos alguns fatos sobre o ensino de Matemática, bem como destacamos o uso da metodologia de ensino da mesma, via Ensino por Atividades.

\subsection{O ENSINO DE MATEMÁtica}

A escola, na atualidade, enfrenta, de modo especial, em relação ao ensino de Matemática, um de seus maiores desafios. Na realidade, é perceptível por todos que, o ensino 
de Matemática não tem surtido o efeito desejado e esperado, um exemplo disso são os resultados insatisfatórios nos processos avaliativos, além do mais, a quantidade de reprovados é elevada.

Outrossim, apesar das dificuldades e desafios pertinentes ao processo de ensino da Matemática, como mencionamos anteriormente, não podemos, por tal fato deixá-la de lado, uma vez que o seu aprendizado é muito útil ao ser humano, que segundo Oliveira, Alves e Neves (2008), por precisar calcular quantidade de animais, alimentos e pessoas, então, por exemplo, conceitos como os de números, percepção de semelhanças e diferenças, instigados por uma necessidade do ser humano, foram surgindo.

O conhecimento matemático é uma ferramenta importante para que o ser humano possa fazer análises e resolver problemas e, sendo assim, a escola, deve buscar ferramentas e meios, isto é, metodologias de ensino, para que, a despeito das dificuldades, os estudantes possam aprender os conceitos matemáticos.

\subsection{O ENSINO POR ATIVIDADES}

Como uma alternativa para o método de ensino de Matemática tradicional, que como foi destacado, tem sido mais motivo de baixos índices e de motivação, em alguns casos, de abandono escolar, o Ensino de Matemática por Atividade surge como uma boa opção metodológica, na qual na concepção de Mendes e Sá (2006), deve ser inserido pelos professores em sala de aula, de modo que a dinâmica de realizar experimentos, por parte dos estudantes, possa fazer com que os mesmos percebam a importância da Matemática e do significado do seu aprendizado. Na concepção de Ronca e Escobar (1988, p. 17), o ensino por atividades tem o poder de "despertar no aluno a capacidade de elaborar sobre as informações, desenvolvendo o seu poder de raciocínio".

O Ensino de Matemática por Atividade, enquanto metodologia de ensino tem como objetivo principal trabalhar os conteúdos matemáticos, de modo que os estudantes possam ser capazes de descobrir, através de mecanismo apresentados pelo professor, as generalizações ou as regras, sem que antes, o professor tenha apresentado tal informação. Nessas condições, quando a Matemática é ensinada por meio de atividades experimentais, o discente vai descobrindo e concluindo, sendo assim, não um sujeito passivo, mas ativo dentro do processo do seu aprendizado.

Ao falar sobre o que acontece durante as ações de uma aula de Matemática, que usa o Ensino por Atividades, Sá (2019) explicita que os conhecimentos prévios dos estudantes devem ser levados em consideração e que, no momento das atividades, professor e estudantes 
interagem bastante durante todo o processo e, principalmente, na parte de institucionalização do conceito.

Sem dúvidas, é importante ressaltar que tais ações contribuem para que os estudantes consigam desenvolver, além do raciocínio matemático, que é importante, também sejam capazes de, após fazerem reflexões, expressarem-se por escrito, fazendo assim uma formalização de um conceito estudado.

Nessa perspectiva de ensino, o professor não encaminha sua aula iniciando pela apresentação de conceitos, seguido de definições, exemplos e exercícios. Neste caso, a aula é introduzida com a apresentação da atividade e, seus itens interrogativos vão conduzindo os estudantes a perceberem e descobrirem uma lei geral ou uma regularidade que, por sua vez, venham a auxiliá-los na compreensão e resolução da mesma.

Como bem pode ser percebido, o Ensino por Atividade, assim como as demais tendências de ensino de Matemática, requer que haja um planejamento, por parte do professor, uma vez que o mesmo, de modo intencional "deve produzir um conjunto de ações que permitam o estudante, após a análises dos resultados das ações, perceber as características do objeto que a atividade tem objetivo de conceituar ou definir" (SÁ, 2019, p. 19).

Ao fazer dessa maneira, acreditamos que o estudante vai construindo/descobrindo noções matemáticas a partir do objetivo proposto para cada atividade, pois pressupõe sua ação direta com as situações apresentadas. Fossa (2000 apud Sobreira e Pereira, 2020, p. 14) também destaca que:

O professor, geralmente, determina a agenda proposta, orienta a construção e valida os resultados, mas ao final das contas é o aluno quem deve fazer as construções. Dessa forma, as avaliações são feitas com o intuito de determinar o que o aluno construiu para que o professor possa determinar como continuar a sua orientação.

Sem dúvidas, tais aspectos tendem a colaborar para que o estudante possa desenvolver habilidades de: analisar, planejar, testar, concluir e generalizar. Para Sá (2009), essa metodologia requer, assim como as demais, planejamento e execução de um plano, no entanto, para que tenhamos uma aprendizagem efetiva, alguns cuidados devem ser considerados para haver um aprendizado efetivo.

O Ensino de Matemática por Atividades, sem dúvidas, requer planejamento e, além do mais, na concepção de Sá (2019), faz-se necessário que o professor possa, para que haja, de fato ensino e aprendizagem, observar alguns momentos importantes durante a ação didática, que são: organização, apresentação, execução, registro, análise e institucionalização. 
No primeiro momento, o da organização, o professor deve organizar, sempre que possível, os estudantes em equipes, onde cada uma deve ter de 2 a 4 participantes. Ao fazer dessa maneira, o docente estará propiciando oportunidades para que os discentes possam trocar ideias entre si, fato que colabora no processo de aprendizagem.

Nesse momento, segundo Sá (2019, p. 15), “o professor deve dirigir as ações, orientar a formação das equipes sem imposições, demonstrar segurança e que planejou com cuidado a atividade e evitar que os estudantes desperdicem tempo com ações alheias a organização da turma”.

No segundo momento, o da apresentação da atividade, professor deverá fazer a distribuição do material didático elaborado por ele, para que assim, os estudantes realizem as tarefas apresentadas. Nessa parte da ação didática, o docente tem que apresentar também, aos discentes, um roteiro para ser seguido pelos mesmos, na realização da tarefa proposta.

Outrossim, é válido salientar que para Sá, (2019, p. 16) "o roteiro pode ser, preferencialmente, impresso ou disponibilizado no quadro o que vai depender das condições estruturais da escola". Nessas condições, concordamos com o autor em questão, uma vez que o instrumento citado oportunizará maior aproveitamento do tempo para que os estudantes leiam as orientações, bem como resolvam as questões apresentadas.

No terceiro momento, o da execução, é quando ocorre a experimentação, nesta etapa cada equipe deve ler o roteiro e realizar os procedimentos estabelecidos para a atividade e onde, segundo, Sá (2019) é quando ocorre manipulação de materiais, medidas, cálculos, observação e/ou comparação.

O papel do professor, nesta etapa, é permitir que as equipes, sobre seu acompanhamento, possam, neste momento, trabalhar com liberdade, mas que, ao mesmo tempo, quando necessário, isto é, se algum estudante desejar ou ele mesmo perceber, possa auxiliar e sanar as dúvidas. Já, os estudantes, devem seguir o roteiro e realizar as tarefas apresentadas.

No quarto momento, o do registro, é a etapa em que acontece a sistematização das informações produzidas durante a experimentação. Neste momento espera-se que cada equipe registre as informações obtidas durante a execução dos procedimentos no respectivo espaço destinado no roteiro (SÁ, 2019, p. 17).

Além do mais, cabe ao professor, momento do registro, ser um supervisor e observar as ações que estão sendo realizadas pelos estudantes. Na etapa em questão, se necessário, assim como no momento anterior, o docente deve sanar eventuais dúvidas que venham a surgir no 
processo; já os estudantes devem fazer, como o próprio nome indica, o registro de uma conclusão sobre o conceito estudado na atividade e, para que o momento em questão seja melhor aproveitado, Sá (2019) recomenda que, o professor, ao elaborar o roteiro com atividade, deixe, ao final da mesma, um espaço para que os discentes realizem seus registros.

No quinto momento, o da análise, para Sá (2019, p. 17) “espera-se que cada equipe analise as informações que foram registradas e percebam as características do objeto matemático que desejar conceituar ou definir entre as informações registradas", no caso de uma atividade de conceituação.

Nesta etapa, assim como nas anteriores, o professor deve ficar atento, para que, caso surjam dúvidas por parte de alguma equipe, o mesmo possa sanar, para que assim, todas as equipes possam, se possível, escrever um registro válido, dentro do conceito estudado.

No sexto momento, o da institucionalização, o professor deve, de posse dos registros e observações que as equipes elaboraram, fazer a apresentação do conceito ou resultado relacionado com a atividade. Um fato a ser notado é que até mesmo pela questão de hábito, os estudantes, tendem nas primeiras aulas via Ensino por Atividade, a ter dificuldade de fazer registros e observações próximos do conceito matemático propriamente dito, mas que a prática, sem dúvidas, ajudará bastante, em outras atividades futuras.

Este é o momento em que o professor deve oportunizar aos estudantes que haja uma troca de informação entre todas as equipes, onde o mesmo "deve solicitar que um representante de cada equipe vá ao quadro e registre a(s) observação(ões) elaborada(s) por sua equipe” (SÁ, 2019, p. 18).

Finalmente, cabe ao professor, ao final da etapa da institucionalização, fazer as devidas observações a respeito dos registros realizados pelos estudantes e, em seguida, apresentar o conceito ou resultado de maneira mais formal e, assim, destacar que, até o momento em questão, não foi realizada nenhuma demonstração. Na oportunidade, quando for possível e couber, o docente, deve apresentar uma demonstração do resultado acessível aos participantes.

\section{Metodologia}

A escola, em que a pesquisa foi realizada, pertence a esfera da administração pública, da rede estadual de ensino e fica localizada no município de Aurora do Pará. Na instituição em questão, no ano de 2017, havia a oferta de turmas do ensino fundamental maior regular e EJA e do ensino médio regular. 
A atividade aqui analisada foi precedida por outras atividades didáticas, que trataram de aspectos da Matemática Financeira com a intenção de garantir os conhecimentos prévios necessários a realização da mesma.

No primeiro dia da experimentação, procuramos construir com os estudantes um contrato didático, de modo que fosse possível proporcionar-lhes a aquisição do conhecimento por meio de suas próprias construções. Para Almouloud (2007, p. 90) "as escolhas pedagógicas, o tipo de trabalho proposto aos alunos, os objetivos de formação, a epistemologia do professor, as condições de avaliação, etc., fazem parte dos determinantes essenciais do contrato didático".

Logo em seguida, fizemos a distribuição de 21 calculadoras científicas, uma para cada estudante e, para que todos tivessem oportunidade de manuseá-la, fizemos uma exploração de algumas funções da mesma e exercitamos alguns cálculos com o instrumento em questão, juntamente com os participantes.

Além disso, dialogamos com os estudantes sobre como as atividades seriam realizadas, bem como a importância da participação deles durante o experimento. Informamos que seriam aplicados dois testes, sendo um antes e o outro após a aplicação da sequência didática.

Um fato em que acreditamos merecer destaque foi logo de início, os estudantes disseram que não estavam acostumados à dinâmica da resolução das questões e alguns começaram a reclamar, entretanto contornamos a situação e explicitamos que, a partir dos dados apresentados em cada questão, eles seriam capazes de resolvê-las, seguindo o passo a passo que estava apresentado em cada parte e, deste modo, a atividade começou a ser realizada. Deste modo, através da interação entre os colegas, das leituras e usando a calculadora as questões foram resolvidas e as conclusões foram sendo organizadas e sistematizadas.

Como bem destacamos, realizamos uma pesquisa com várias atividades, dentro da Matemática Financeira, com temas que serviram de pré-requisito para atividade sobre o valor do dinheiro no tempo, as quais, destacamos, principalmente as atividades sobre inflação e juros compostos.

$\mathrm{Na}$ realidade, os desafios para que tenhamos uma aprendizagem significativa, são grandes, mas com planejamento das ações fica mais viável atingir tal objetivo, como foi, no caso em que nos propomos, nesta atividade específica, a mostrar aos estudantes sobre um importante conceito, o valor do dinheiro no tempo. 
Como já explicitamos, na pesquisa, aplicamos um conjunto de várias atividades, 10 , para sermos mais precisos, em que tivemos a participação de 24 estudantes do $3^{\circ}$ ano de uma escola pública, localizada no nordeste paraense.

Para desenvolvimento dessa atividade, usamos 71 minutos, em que os estudantes responderam 10 questões e realizaram, como requer o Ensino por Atividades, usado por nós no trabalho em questão, uma conclusão sobre o tema abordado durante a atividade apresentada.

A seguir, explicitaremos a atividade, apresentando as questões, bem como fazendo algumas análises e recomendações didáticas.

\subsection{O VALOR DO DINHEIRO NO TEMPO}

Objetivo: Apresentar o valor do dinheiro no tempo.

Material: Papel, caneta e/ou lápis e calculadora.

Procedimento: Com auxílio da calculadora, resolva as questões a seguir:

Quadro 1 - Questões propostas na atividade

1 - O que seria melhor: $\mathrm{R} \$ 100,00$ em janeiro de 2000 ou $\mathrm{R} \$ 280,00$ em janeiro de 2016 ?

2 - Qual o maior poder de compra: de R \$500,00 em março de 2005 ou de $\mathrm{R} \$ 600,00$ em janeiro de 2008 ?

3 - Complete o quadro a seguir:

\begin{tabular}{|l|c|c|l|}
\hline Ano & Valor do SM & VM da CB em Belém & $\mathrm{N}^{\circ}$ de CB compradas com um SM \\
\hline 1995 & $\mathrm{R} \$ 100,00$ & $\mathrm{R} \$ 80,73$ & \\
\hline 2000 & $\mathrm{R} \$ 151,00$ & $\mathrm{R} \$ 99,04$ & \\
\hline 2005 & $\mathrm{R} \$ 300,00$ & $\mathrm{R} \$ 152,25$ & \\
\hline 2010 & $\mathrm{R} \$ 510,00$ & $\mathrm{R} \$ 216,13$ & \\
\hline 2013 & $\mathrm{R} \$ 678,00$ & $\mathrm{R} \$ 296,43$ & \\
\hline 2014 & $\mathrm{R} \$ 724,00$ & $\mathrm{R} \$ 305,44$ & \\
\hline 2015 & $\mathrm{R} \$ 788,00$ & $\mathrm{R} \$ 331,33$ & \\
\hline 2016 & $\mathrm{R} \$ 880,00$ & $\mathrm{R} \$ 412,01$ & \\
\hline
\end{tabular}

4 - Observe os dados a seguir, que apresentam as informações de acordo com a correção, do valor da moeda, pelo IPCA e os valores monetários são expressos em reais:

\begin{tabular}{|c|c|c|c|c|c|c|c|c|c|}
\hline Mês & $01 / 1995$ & $01 / 1996$ & $01 / 2000$ & $01 / 2002$ & $01 / 2006$ & $01 / 2009$ & $01 / 2014$ & $01 / 2016$ & $01 / 2017$ \\
\hline Valor & 100,00 & 124,47 & 158,32 & 180,43 & 252,47 & 287,57 & 379,09 & 447,91 & 474,51 \\
\hline
\end{tabular}

De acordo com as informações apresentadas, uma pessoa que conseguia em janeiro de 1995 fazer uma compra com $\mathrm{R} \$ 100,00$ (salário mínimo no referido ano). Qual deveria ser o valor a ser usado para a realização a mesma compra:

a) em 1996? b) em 2000? c) em 2002? d) em 2006?

e) em 2009? f) em 2014? g) em 2016? h) em 2017?

5 - Observe os dados a seguir, que apresentam as informações de acordo com a desvalorização, do valor da moeda, pelo IPCA e os valores monetários são expressos em reais:

\begin{tabular}{|l|c|c|c|c|c|c|c|c|c|}
\hline Mês & $01 / 1995$ & $01 / 1996$ & $01 / 2000$ & $01 / 2002$ & $01 / 2006$ & $01 / 2009$ & $01 / 2014$ & $01 / 2016$ & $01 / 2017$ \\
\hline Valor & 100,00 & 80,34 & 63,16 & 55,42 & 28,37 & 25,81 & 20,87 & 18,25 & 17,35 \\
\hline
\end{tabular}

De acordo com as informações apresentadas, uma pessoa que guardara $\mathrm{R} \$ 100,00$ em casa em janeiro de 1995, então: Qual o poder de compra dos R \$100,00:

a) em 1996? b) em 2000? c) em 2002? d) em 2006?

e) em 2009? f) em 2014? g) em 2016? h) em 2017? 
6 - Uma mercadoria, à vista, custa $\mathrm{R} \$ 1.000,00 \mathrm{em}$ uma loja. Se você dispõe do valor para pagar o produto à vista e que consegue uma renda de $5 \%$ ao mês, então é melhor pagar à vista ou pagar, daqui a um mês: a) $\mathrm{R} \$$ $1.100,00$ ? b) $\mathrm{R} \$ 1.050,00$ ? c) $\mathrm{R} \$ 1.030,00$ ?

7 - Uma pessoa consegue fazer seu dinheiro render $2 \%$ ao mês. Se ele aplicou R $\$ 500,00$. Qual:

a) O fator de correção no primeiro mês? b) O valor dos R $\$ 500,00$ após um mês?

c) $\mathrm{O}$ fator de correção acumulado nos dois primeiros meses?

d) O valor dos $\mathrm{R} \$ 500,00$ após os dois primeiros meses?

8 - Uma pessoa conseguira fazer seu dinheiro render $2 \%$ ao mês. Se, após 5 meses de uma aplicação, o mesmo resgatou o total de $\mathrm{R} \$ 552,04$. Qual era o valor que ele poderia resgatar no final do:

a) Quarto mês de investimento? b) Terceiro mês de investimento?

c) Segundo mês de investimento? d) Primeiro mês de investimento?

e) Quanto ele aplicou?

9 - Como encontrar o valor obtido na letra e da questão 8, com um número reduzido de operações?

10 - Uma pessoa consegue aplicar seu dinheiro a $2 \%$ ao mês e irá pagar $\mathrm{R} \$ 500,00$ daqui a um mês e mais $\mathrm{R} \$ 500,00$ daqui a dois meses. Quanto deve depositar hoje?

Conclusão:

Fonte: Sobreira (2018)

O Ensino de Matemática por Atividades, como bem destacamos, é dividido em etapas, então, no momento da organização, o primeiro deles, fizemos a divisão dos estudantes em grupos de três componentes, como bem sugeriu Sá (2019) e, na oportunidade, salientamos a necessidade de que os mesmos, ao longo da atividade, fossem trocando ideias entre si. Além do mais, em seguida, fizemos o segundo momento, que foi a distribuição do roteiro da atividade em que iríamos trabalhar e, cada estudante recebeu as questões apresentadas no Quadro 1, bem como as informações complementares explicitadas nos Quadros 2 e 3 e na Figura 1.

Além disso, para que os estudantes tivessem a percepção de que uma nota de dinheiro, mesmo com o valor numérico inalterado, muda de valor, ao longo do tempo, iniciamos a atividade apresentado algumas informações sobre o valor, isto é, o poder de compra, pois é o que realmente tem importância, de uma nota de R\$ 100,00 no ano de 1994 em 2016, que foi o ano anterior a realização da nossa pesquisa. Os detalhes estão apresentados no Quadro 2.

Quadro 2 - Sobre o valor de $\mathrm{R} \$ 100,00$

Desde $1^{\circ}$ de julho de 1994, quando o real começou a circular, até 31 de março de 2016, a moeda brasileira perdeu $81,41 \%$ do seu poder de compra, segundo cálculo do Instituto Assaf. Por causa da desvalorização, uma nota de $\mathrm{R} \$ 100$ tem poder de compra equivalente a $\mathrm{R} \$ 18,59$ atualmente. "Se alguém tivesse deixado uma nota de $\mathrm{R} \$ 100$ guardada durante todo esse tempo, ela teria, hoje, menos de um quinto do valor de 1994. Tal situação ocorreu devido à atuação da inflação dos últimos anos.

Fonte: https://economia.uol.com.br/noticias/redacao/2016/04/12/inflacao-de-438-desde-criacao-do-real-faz-notade-r-100-valer-r-1859.htm. Acesso em: 15 de nov. 2017 
O texto anterior, era acompanhado da Figura 1, expressa a seguir.

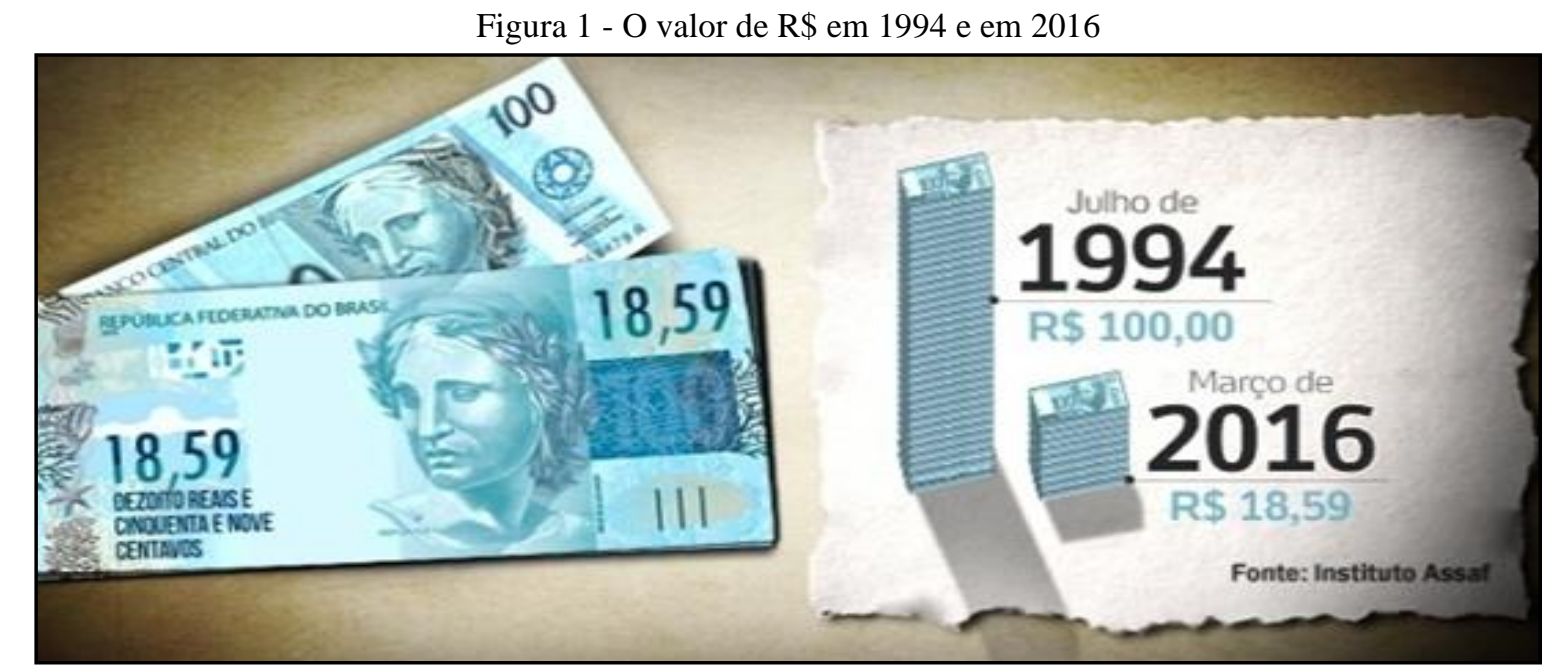

Fonte: https://economia.uol.com.br/noticias/redacao/2016/04/12/inflacao-de-438-desde-criacao-do-real-faz-notade-r-100-valer-r-1859.htm. Acesso em: 15 de nov. 2017

No terceiro momento, o da execução, os estudantes, de posse do roteiro, começaram, em suas equipes, a fazer a leitura do material, observando o passo a passo e, assim, buscando resolver as questões propostas. Após as discussões pertinentes ao problema 1, que foram, do tipo: como saber isso professor? Será que os $\mathrm{R} \$ 280,00$ não seriam o melhor, por ser o maior valor? Será que que os R \$100,00, há muito tempo, não seriam melhor? Então, propusemos, o problema 2, apresentando-lhes uma situação que proporcionasse aos estudantes um debater sobre o poder de compra de dois valores diferentes, em épocas distintas, fato que já havia sido também destacado no problema 1, mas que, agora a diferença temporal e dos valores monetários foram menores. Salientamos que o anteriormente tema inflação já havia sido tratado em outra atividade anterior.

Os problemas 1 e 2, os quais mencionamos anteriormente proporcionaram discussões entre todos os participantes, onde, na essência, os estudantes disseram que fatores como taxas de juros e inflação teriam que ser conhecidos para que, de fato, as respostas fossem mais precisas.

Esses dois primeiros problemas foram para iniciar o debate, não havia propriamente, que sem analisemos outros fatores como taxas de juros e inflação, uma resposta correta, sendo assim, a nossa expectativa era que os discentes, logo de início, lembrassem de outras atividades já trabalhadas, as quais citamos aqui e eles conseguiram estabelecer a relação entre o valor da cédula e a questão do tempo, que muda o poder de compra do dinheiro. 
Após as discussões pertinentes ao problema 2, que foram, do tipo: será que o valor de $\mathrm{R} \$ 600,00$ não seria melhor do que o de $\mathrm{R} \$ 500,00$, uma vez que 600 é um número maior do que o 500? Será, professor, que os 500, por ser bem perto de 600 e ser recebido três anos antes, não seria melhor?

Após tais discussões, referentes aos dois primeiros problemas, os estudantes resolveram o problema 3 que apresentou algumas informações importantes sobre o salário mínimo, destacando pontos históricos, bem como sua importância e além disso, qual deveria ser o valor do mesmo no período da aplicação da atividade. Queríamos que os estudantes percebessem que ainda estamos, de acordo com a lei, com um salário mínimo aquém do necessário. Para apresentar informações sobre aspectos legais do salário mínimo e de sua variação foram apresentadas as informações constantes do Quadro 3.

Quadro 3 - Informações complementares

No Brasil, a lei no 185 , de 14 de janeiro de 1936 criara o salário mínimo (SM), que segundo seu art. $1^{\circ}$ esse valor ser capaz deveria de satisfazer, as suas necessidades normais de alimentação, habitação, vestuário, higiene e transporte. De acordo com a lei, os estudos do Departamento Intersindical de Estatística e Estudos Socioeconômicos (DIEESE), em setembro, o salário mínimo ideal para sustentar uma família de quatro pessoas deveria ter sido de $\mathrm{R} \$ 3.668,55$, no entanto esse valor é 3,92 vezes o salário em vigor atualmente, que é de $\mathrm{R} \$ 937$.

Fonte: https://economia.uol.com.br/empregos-e-carreiras/noticias/redacao/2017/10/04/salario-minimo-setembrodieese.htm. Acesso: 15 de nov de 2017.

O problema 3, que apresentou um questionamento relativo ao poder de compra salário mínimo, em Belém, tendo como parâmetro o valor da cesta básica na capital paraense, foi respondido por todos os estudantes. O nosso objetivo em apresentar tal problema era que os estudantes percebessem que, mesmo o valor da cesta básica, em termos numérico, ter subido, assim como o valor do salário mínimo nacional, o poder de compra do mesmo, na referida cidade, tendo o parâmetro em questão, ao longo do tempo em destaque, subiu.

$\mathrm{Na}$ questão em destaque, algumas equipes tiveram dificuldades de interpretação sobre qual deveria ser a operação matemática usada e, fomos fazendo colocando, de modo oral, algumas situações, tais como: quantas vezes o 2 cabe no 4 ? O 10, cabe quantas vezes o 5 ? E, dessa maneira os mesmos puderam ter as dificuldades minimizadas e entenderam que deveriam fazer, para resolver a situação que lhes fora apresentada, uma divisão.

Ao resolverem a situação apresentada, os discentes começaram a perceber de que o valor do salário mínimo, ao longo dos anos, subiu, mas que o valor da cesta básica também subiu e que, assim, não adiantava nem o salário mínimo subir, pois as coisas também subiam, mas, ao resolver a situação em debate, perceberam que a razão entre o valor do salário mínimo e o da 
cesta básica aumentou, então começaram a explanar de que o salário mínimo, nos anos apresentados, aumentou o poder de compra, tendo como base o parâmetro usado.

A questão 4 foi sobre a reposição do valor salário mínimo, pelo IPCA, em alguns anos. O nosso objetivo era que os estudantes, ao resolverem tal situação, percebessem que, se o salário mínimo tivesse sido reajustado apenas pela inflação, em janeiro de 2017, o mesmo teria sido, aproximadamente $R \$ 475,00$, bem abaixo do valor de fato, que foi de $R \$ 937,00$, ou seja, que, na verdade, nos anos em questão, no Brasil, houve um aumento real do valor do salário mínimo.

Em seguida, propusemos o problema 5, em que os estudantes resolveram uma questão sobre como a inflação, medida pelo IPCA, influenciou no poder de compra de uma cédula cujo valor é R\$ 100,00. O nosso objetivo era que os estudantes, ao resolverem tal problema, percebessem que, ao longo dos anos, pela ação inflação, o dinheiro, perde o poder de compra.

Em face das informações apresentadas nas questões 4 e 5, os estudantes, não apresentaram, praticamente, nenhuma dúvida nas resoluções das mesmas.

Os problemas 4 e 5, que apresentaram questionamentos sobre o poder de compra de uma cédula de $\mathrm{R} \$ 100,00$, bem como o reajuste que deveria ser dado ao mesmo valor para a manutenção do poder de compra, foram respondidos por todos os estudantes. No momento em que resolviam as situações apresentadas, em face da percepção de que, em 1995, o valor do salário mínimo foi exatamente R \$ 100,00, então comentaram de que, em 2017, o salário mínimo deveria ser, cerca de $\mathrm{R} \$ 475,00$ e não o valor vigente em 2017, que foi $\mathrm{R} \$ 937,00$. Aproveitando a oportunidade sugerimos que eles pesquisassem sobre a lei do teto de gastos, bem como as ideias neoliberais e estado mínimo e salientamos que, no Brasil, alguns estudiosos da economia achavam que, de fato o salário mínimo deveria ser, naquele ano, menos de $\mathrm{R} \$ 500,00$.

O problema 6 foi uma questão em que os estudantes foram desafiados a resolverem uma situação em que, uma certa loja, apresentava uma proposta de pagamento de um produto. $\mathrm{O}$ nosso objetivo era que os estudantes, ao resolverem tal problema, percebessem que, a depender das condições, dentre elas o tempo e a taxa de juros, uma compra à vista pode ser a melhor escolha, mas que em outros casos, pagar depois pode ser a melhor opção.

O problema em questão, que apresentou um questionamento sobre uma proposta de pagamento de um produto, oferecido por uma loja. Os estudantes debateram bastante, uma vez que é uma situação bem presente ao cotidiano dos mesmos e, logo no início, acharam que seria melhor optar por pagar os $\mathrm{R} \$ 1000,00$, pois era o menor valor entre os que foram apresentados na situação. Na resolução alguns perguntaram se poderiam usar o fator de correção, que já 
havíamos debatido anteriormente e, em seguida, nessa questão, conseguiram fazer a devida resolução, sem mais questionamentos.

Em seguida, na proposição do problema 7, pretendíamos que os discentes resolvessem um caso que envolvia a correção do valor do dinheiro depositado, muda mês a mês, a depender da taxa que a instituição paga de juros.

O problema em questão apresentou um questionamento sobre o rendimento de um depósito no valor de $\mathrm{R} \$ 500,00$ ao longo de dois meses. Nesse caso, em face de termos, como bem destacamos outras atividades que, no âmbito da Matemática Financeira, já tinham sido trabalhadas, de modo especial, o fator de correção e, nesse caso, ainda mais como haviam aplicado na questão anterior, mais uma vez, os estudantes aplicaram-no e fizeram a resolução da questão que proposta.

Quando propusemos o problema 8 pretendíamos que os estudantes resolvessem uma situação cujo o objetivo foi fazer com os mesmos analisassem a questão de capitalização, a partir de um único depósito. Em seguida, ao aplicarmos o problema 9, desafiamos aos estudantes para que os mesmos analisassem sobre a possiblidade de encontrar a resposta dada ao item e do problema anterior de modo mais direto, uma vez que tão situação encontra-se bem presente nas diversas relações que envolvem taxas, dinheiro e tempo.

O problema 8, propôs, digamos assim, uma situação inversa ao que propusemos no problema 7 e, em face disso, alguns estudantes, por não perceberem a inversão, isto é, trazer um valor futuro para o presente, tentaram aplicar o fator de correção, como fizeram na questão anterior, mas, desafiamo-los, a uma releitura do que a questão solicitava e, ainda, auxiliamolos no processo da segunda leitura.

Em consequência dos fatos destacados, todos os estudantes, sem muito debate, em face da similaridade, conseguiram fazer a resolução, sem que apresentassem dúvidas relevantes. $\mathrm{O}$ problema 9, consistiu da generalização relativa à questão anterior.

E, no último problema, propusemos aos estudantes uma questão para que os mesmos resolvessem e que versou sobre a capitalização em dois depósitos em épocas diferentes e que estariam aplicados a mesma taxa, mas com períodos distintos. O nosso objetivo era que os estudantes, ao resolverem tal problema, percebessem que, o primeiro depósito, ao final dos dois meses, se transformou em um valor maior que o segundo, devido à diferença temporal. 
Em seguida, após a resolução dos problemas, cada equipe iniciou a participação de outro momento, o de registro, onde os estudantes buscaram fazer uma sistematização de todas as informações produzidas, em face dos questionamentos, por eles.

O problema em análise, que apresentou um questionamento sobre o pagamento de uma dívida em dois pagamentos de $\mathrm{R} \$ 500,00$ cada um, sendo o primeiro com um mês e, o segundo, com mais um mês após o primeiro. Logo no início os estudantes, sem muita discussão disseram que deveria ser R \$1000,00, pois equivaleria à soma entre os dois valores em questão, mas, após sugerirmos que os mesmos relessem e observassem as informações presentes, os mesmos perceberam que havia a questão da taxa e, assim, mais uma vez perguntaram sobre o uso do fator de correção e, em seguida, conseguiram desenvolver o processo para resolver a questão.

No momento em questão, como recomenda Sá (2019), fizemos a supervisão das equipes, buscando auxiliá-las e sanar possíveis dúvidas e questionamentos. Além do mais, como bem pode ser percebido no Quadro 1, para facilitar os registros, ao final da atividade, deixamos um espaço, dentro do roteiro distribuído aos estudantes, para que, fossem realizadas as conclusões.

\section{Resultados}

No encontro, em que aplicamos a atividade em questão, tínhamos como objetivo de apresentar, a partir de problemas reais do contexto dos estudantes situações que propiciassem fazer a verificação de que o valor de compra do dinheiro muda com o passar do tempo, pois alguns fatores como juros, inflação são decisivos na situação. Sendo assim, com auxílio da calculadora, foi possível, através do trabalho em equipe, onde os estudantes puderam interagir entre si e trocar ideias de como resolver as diversas situações apresentadas sobre o tema em questão e, como consequência, ao perceber certas regularidades no processo, fosse possível enunciar uma regra de como fazer uma avaliação de como o valor do dinheiro, isto é, do poder de compra do mesmo, muda com o tempo.

$\mathrm{Na}$ análise a priori da atividade, esperávamos que os estudantes fossem capazes de entender que o estudo das taxas leva em consideração o fator de aumento e a inflação. Nesta atividade foram explicitados textos informativos sobre o que vem a ser a cesta básica e sua relação com o poder de compra do salário mínimo, apresentado inclusive uma série histórica sobre a relação entre o valor da cesta básica e o valor do salário mínimo em Belém, de modo que os estudantes perceberam que nem sempre quando o salário sobe, na verdade o poder de compra vai junto com o aumento dado. 
Ao realizarmos esta atividade, que foi a sétima, realizada em nosso oitavo encontro, os estudantes estavam bem acostumados ao método de ensino em questão e participaram bastante de todo o processo. A atividade em análise foi composta por 10 questões, onde, apresentaremos a seguir, os resultados das resoluções dos itens de 3 a 10. Como os itens 1 e 2 foram apenas para reflexões e debates, então, a questão de erros e acertos, não foram considerados.

Quadro 4 - Desempenho na resolução de questões
\begin{tabular}{|c|c|c|}
\hline Problema/Questão & Acertos (\%) & Erro (\%) \\
\hline 3 & 100,00 & 0,00 \\
\hline 4 & 100,00 & 0,00 \\
\hline 5 & 100,00 & 0,00 \\
\hline 6 & 80,95 & 19,05 \\
\hline 7 & 80,95 & 19,05 \\
\hline 8 & 100,00 & 0,00 \\
\hline 9 & 90,48 & 9,52 \\
\hline 10 & 100,00 & 0,00 \\
\hline
\end{tabular}

Fonte: Pesquisa de campo (2017)

As informações explicitadas no Quadro 4 nos mostram que, entre os estudantes que estavam presentes no dia da realização da atividade em questão, a média de acertos foi de, aproximadamente, 94\%. A seguir, vamos apresentar algumas resoluções de problemas/questões que fizeram parte da atividade e que foram realizadas pelos estudantes. Salientamos que, em nosso trabalho, para facilitar o acompanhamento da pesquisa, cada participante recebeu um código, A1, A2, A3 e até o A24.

Agora apresentaremos alguns casos e, em seguida, algumas reflexões.

Quadro 5 - Problema 10, resolvido pelo estudante A14

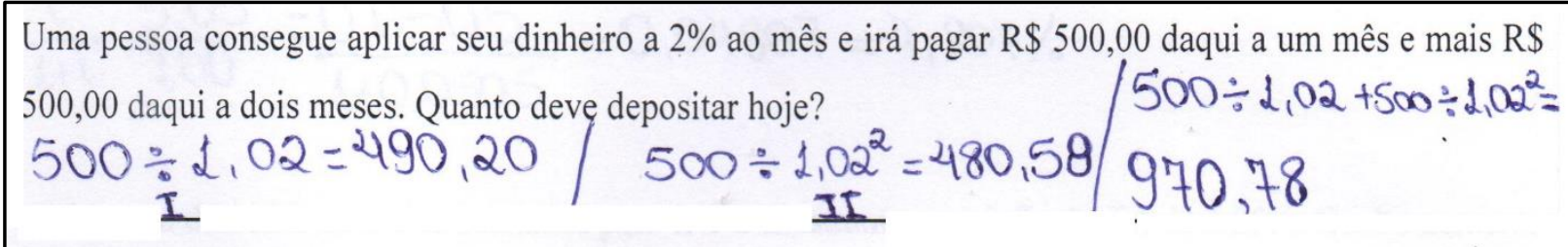

Fonte: Pesquisa de campo (2017).

Esta questão, todos os estudantes conseguiram acertar todos os itens que lhes foram apresentados. A seguir, no Quadro 6, apresentamos uma resolução do problema 6. 
Quadro 6 - Problema 6, resolvido pelo estudante A2

Uma mercadoria custa $\mathrm{R} \$ 1.000,00$ em uma loja. Se você encontra-se com 0 valor para pagar o produto à vista e que consegue uma renda de $5 \%$ ao mês, então é melhor pagar à vista ou pagar:

a) $R \$ 1.100,00$ daqui a um mês? ·

naio vai dar de pagar, pois vai faltar dirkerro

b) $\mathrm{R} \$ 1.050,00$ daqui a um mês?

So iná do de pagar, e mấ urá noluar nada.

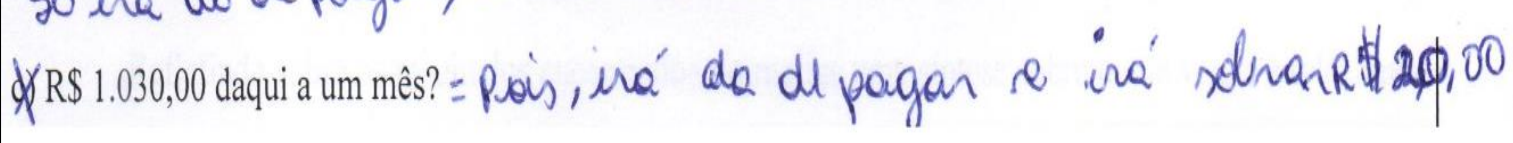

Fonte: Pesquisa de campo (2017).

Em relação à questão anterior, os erros cometidos pelos estudantes foram, na verdade, a resolução de modo parcial da questão, geralmente somente com resposta a letra a. A seguir, no Quadro 7, apresentamos uma resolução do problema 7.

Quadro 7 - Problema 7, resolvido pelo estudante A2

Uma pessoa consegue fazer seu dinheiro render $2 \%$ ao mês. Se ele aplicara $R \$ 500,00$.

a) Qual o fator de correção no primeiro mês?

\section{1,02}

b) Qual o valor dos $\mathrm{R} \$ 500,00$ após um mês?

$500 \times 1,02=R \$ 510,00$

c) Qual o fator de correção acumulado nos dois primeiros meses?

$$
1.02 \times 1,02=1,0404
$$

d) Qual o valor dos $\mathrm{R} \$ 500,00$ após os dois primeiros meses?
$510 \times 1,02=520,20 \mathrm{R} \$) / 500 \times 1,02 \times 1,02=R \$ 520,20$

\section{Fonte: Pesquisa de campo (2017).}

Em relação à questão anterior, os erros cometidos pelos estudantes de dois tipos, um deles fez confundiu o fator de aumento acumulado, como a porcentagem de aumento e ainda multiplicou o resultado encontrado por 10, dando como resposta 0,404 no lugar de 1,0404 e assim, consequentemente, errou também a letra seguinte, na questão; já os outros três, esqueceram de colocar a vírgula na escrita decimal de alguns resultados, em especial do último item. A seguir, no Quadro 8, apresentamos uma resolução do problema 8. 
Quadro 8 - Problema 8, resolvido pelo estudante A11

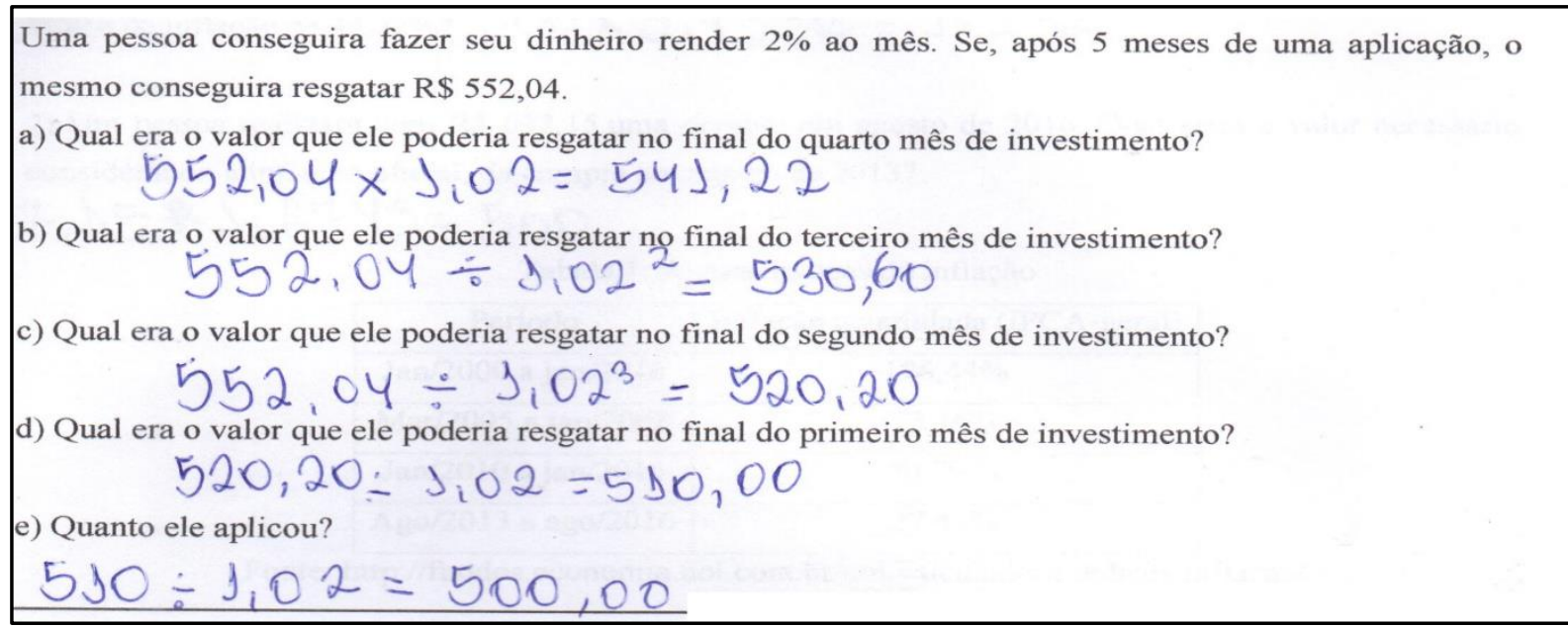

Fonte: Pesquisa de campo (2017).

Esta questão, todos os estudantes conseguiram acertar todos os itens que lhes foram apresentados. A seguir, no Quadro 9, apresentamos uma resolução do problema 3.

Quadro 9 - Problema 3, resolvido pelo estudante A22

Complete a tabela a seguir:
\begin{tabular}{|l|c|c|c|}
\hline Ano & Valor do SM & VM da CB em Belém & $N^{\circ}$ de CB compradas com um SM \\
\hline 1995 & $\mathrm{R} \$ 100,00$ & $\mathrm{R} \$ 80,73$ & $100 \div 80,73=1,239$ \\
\hline 2000 & $\mathrm{R} \$ 151,00$ & $\mathrm{R} \$ 99,04$ & $51 \div 99,04=1,525$ \\
\hline 2005 & $\mathrm{R} \$ 300,00$ & $\mathrm{R} \$ 152,25$ & $300 \div 152,25=4,970$ \\
\hline 2010 & $\mathrm{R} \$ 510,00$ & $\mathrm{R} \$ 216,13$ & $500 \div 216,17=2,3,60$ \\
\hline 2013 & $\mathrm{R} \$ 678,00$ & $\mathrm{R} \$ 296,43$ & $678 \div 296,43=2,287$ \\
\hline 2014 & $\mathrm{R} \$ 724,00$ & $\mathrm{R} \$ 305,44$ & $724 \div 305,44=2,370$ \\
\hline 2015 & $\mathrm{R} \$ 788,00$ & $\mathrm{R} \$ 331,33$ & $788 \div 331,33=2.378$ \\
\hline 2016 & $\mathrm{R} \$ 880,00$ & $\mathrm{R} \$ 412,01$ & $880 \div 442,01=2,136$ \\
\hline
\end{tabular}

Fonte: Pesquisa de campo (2017).

Esta questão, todos os estudantes conseguiram acertar todos os itens que lhes foram apresentados. As informações explicitadas nos Quadros 6, 7, 8 e 9 nos apresentam algumas resoluções de questões que fizeram parte da atividade. As imagens nos mostram que os estudantes conseguiram entender o conceito abordado sobre o valor do dinheiro no tempo e, para que isso fique mais evidente, a seguir, vamos apresentar as conclusões que os discentes realizaram ao final da atividade.

Ao final da atividade, os estudantes, foram desafiados a realizarem registros, que, no Ensino por Atividade, denominamos conclusão. A seguir, destacaremos as anotações dos estudantes que participaram da atividade. Preferimos, por uma questão de visualização, fazer tais anotações digitadas. 
Quadro 10 - Registro das conclusões dos estudantes sobre o valor do dinheiro no tempo

\begin{tabular}{|c|c|c|}
\hline Participantes & Análises & Validade \\
\hline $\mathrm{A} 1, \mathrm{~A} 5, \mathrm{~A} 8$ & $\begin{array}{l}\text { O valor do dinheiro não depende exclusivamente do número escrito na } \\
\text { cédula }\end{array}$ & Válida \\
\hline $\mathrm{A} 4, \mathrm{~A} 9, \mathrm{~A} 15$ & $\begin{array}{l}\text { Com o tempo o dinheiro tende a perder o valor de compra, a menos } \\
\text { que seja reajustado pela inflação }\end{array}$ & Válida \\
\hline $\mathrm{A} 7, \mathrm{~A} 14, \mathrm{~A} 24$ & $*$ & $\begin{array}{c}\text { Não } \\
\text { realizaram }\end{array}$ \\
\hline $\mathrm{A} 12, \mathrm{~A} 16, \mathrm{~A} 20$ & $\begin{array}{l}\text { A inflação e o tempo influenciam no valor do dinheiro, às vezes o } \\
\text { salário sobe, mas o valor de compra diminui }\end{array}$ & Válida \\
\hline $\mathrm{A} 17, \mathrm{~A} 19, \mathrm{~A} 23$ & $\begin{array}{l}\text { O valor do dinheiro vai além do número escrito na nota, o tempo e a } \\
\text { inflação também influenciam no valor do dinheiro }\end{array}$ & Válida \\
\hline A11,A13, A18 & $\begin{array}{l}\text { Inflação e juros influenciam no valor do dinheiro com o passar do } \\
\text { tempo }\end{array}$ & Válida \\
\hline $\mathrm{A} 6, \mathrm{~A} 21, \mathrm{~A} 22$ & O valor do dinheiro depende de fatores como juros, inflação e tempo & Válida \\
\hline
\end{tabular}

Fonte: Sobreira (2018, p. 305-306)

As informações explicitadas anteriormente nos indicam de que os estudantes conseguiram assimilar o conceito matemático que lhes foi apresentado, uma vez que, dos 21 que estavam presentes no dia da realização da atividade, aproximadamente, $86 \%$ deles, conseguiram realizar uma conclusão válida e, uma das equipes, não realizou o registro final, deixando-o em branco.

Ao considerarmos os tipos de conclusões apresentadas pelos estudantes, resolvemos organizá-las, para melhor entendimento, em um quadro. Eis os detalhes:

Quadro 11 - Validade das conclusões da atividade

\begin{tabular}{|l|c|c|}
\hline Tipo de conclusão & Quantidade de estudantes & $\%$ \\
\hline Válida & 18 & 85,71 \\
\hline Não realizou & 3 & 14,28 \\
\hline
\end{tabular}

Fonte: Sobreira (2018, p. 307)

As informações destacadas anteriormente nos possibilitaram inferir, em face dos que realizaram a conclusão válida, que na verdade foram $100 \%$ dos que fizeram os registros no final da atividade, que o conceito relativo ao valor do dinheiro o tempo foi compreendido pelos estudantes.

\section{CONSIDERAÇões FinAIS}

Este trabalho apresentou algumas análises sobre a aplicação de atividade, com os estudantes do $3^{\circ}$ ano do Ensino Médio de uma escola pública, onde tínhamos como objetivo analisar os resultados da aplicação de questões, usando como metodologia de ensino de Matemática, o Ensino por Atividades, para que assim pudéssemos trabalhar o conceito 
pertinente à noção de valor do dinheiro no tempo. O tema em questão é muito importante, pois quando uma pessoa vai fazer uma compra ou vai tomar uma decisão de como efetuar um plano de pagamentos qualquer, precisa fazer reflexões a respeito do assunto em questão.

O Ensino de Matemática por Atividades, que como bem mencionamos, foi usada nesse trabalho para que os estudantes tivessem contato com o tema relativo ao valor do dinheiro no tempo, proporcionou-lhes uma grande interação entre as esquipes e entre os discentes e, além disso, deu-lhes a oportunidade de, após resolver questões, fazer generalizações e registros, a respeito do conceito em que estávamos trabalhando, o que, sem dúvidas, irá auxiliá-los em outras situações semelhantes, no futuro.

Outrossim, tendo em vista os resultados apresentados, podemos inferir que os estudantes, ao longo das resoluções das questões, bem como nos registros realizados, conseguiram assimilar o conceito que nos propomos a trabalhar com eles, ou seja, o nosso objetivo de fazer uma análise sobre os resultados da aplicação de uma atividade para trabalhar a noção de valor do dinheiro no tempo foi alcançado e nos mostrou que na ação didática realizada com os estudantes aconteceu aprendizagem, pois os mesmos, ao final da resolução das questões, após reflexões e debates em grupos, conseguiram fazer anotações e generalizações sobre o conceito ministrado na atividade.

Além disso, quando levamos em consideração as resoluções das questões propostas pelos estudantes, nas quais foram aqui apresentadas, podemos dizer que os discentes entenderam que o valor do dinheiro, vai além do número escrito na cédula, uma vez que, com tempo muitos fatores, como inflação, interferem diretamente no poder de compra do dinheiro, fato que é o mais importante, uma vez que o valor do dinheiro é, na verdade, aquilo que conseguimos comprar através dele.

A aplicação da atividade em questão, em face de fatores relacionados as condições tecnológicas da escola, como falta de laboratório de informática ou até mesmo uma rede de internet móvel para que os estudantes acessassem, limitou-se ao uso dos recursos didáticos convencionais, além do uso de uma calculadora científica básica.

Outrossim, acreditamos que com uso de outras ferramentas, como uma calculadora disponível no Banco Central do Brasil, que calcula, baseado em vários índices de inflação, o valor do dinheiro no tempo, teríamos realizado outras análises sobre o tema que apresentamos.

Em face do exposto, acreditamos que o experimento didático que foi apresentado, poderá, sem dúvidas, ser replicado por nossos colegas professores, sendo feitas as devidas 
adequações e uso de outros recursos tecnológicos, como aqui mencionamos e, sendo assim, por acreditarmos na força da educação, temos a percepção de que cada vez mais, ao proporcionar debates como os que foram explicitados nessa atividade, teremos estudantes capazes de, quando necessário, fazer cobranças e exigir direitos, fatos tão importantes no exercício da cidadania.

Finalmente, sugerimos, com mais recursos didáticos, como planilhas eletrônicas e a calculador disponível do site do Banco Central do Brasil, já mencionada, que possamos fazer outras aplicações e pesquisas sobre o tema aqui debatido, até mesmo no ensino fundamental, pois dessa maneira, possivelmente poderemos proporcionar debates com um número maior de estudantes, bem como colher novas percepções e, também, outras generalizações por parte dos estudantes, de modo que os mesmos possam, com novos desafios, inclusive mais atuais, como a questão da lei de teto dos investimentos públicos no Brasil, perceberem o conceito trabalhado, bem como os efeitos práticos na vida de cada um de nós e de nossas comunidades.

\section{REFERÊNCIAS}

ALMOULOUD, Saddo Ag. Fundamentos da didática da Matemática. Curitiba: UFPR, 2007.

BRASIL. Base Nacional Comum Curricular (BNCC). Educação é a Base. Brasília, MEC/CONSED/UNDIME, 2017. Disponível em:

http://basenacionalcomum.mec.gov.br/images/BNCC_EI_EF_110518_versaofinal_site.pdf. Acesso em: 26 ago. 2019.

BRASIL. Diretrizes Curriculares Nacionais para a Educação Básica. Brasília: MEC, SEB, DICEI, 2013.

BRASIL. Ministério da Educação. Secretaria de Educação Média e Tecnológica. Parâmetros curriculares nacionais: ensino médio. Brasília: MEC-SEMTEC, 1999.

BRASIL. Parâmetros Curriculares Nacionais: Ensino Médio, Ciências da Natureza, Matemática e suas Tecnologias. Brasília: MEC, 2000.

MENDES, Iran Abreu; SÁ, Pedro Franco de. Matemática por atividades: sugestões para sala de aula. Natal: Flecha do Tempo, 2006.

OLIVEIRA, José Sávio Bicho; ALVES, Ângela Xavier; NEVES, Sandra do Socorro de Miranda. História da Matemática: contribuições e descobertas para o ensino-aprendizagem de matemática. Belém, SBEM, 2008. Disponível em: https://docplayer.com.br/5142495Historia-da-matematica-contribuicoes-e-descobertas-para-o-ensino-aprendizagem-dematematica.html. Acesso em: 15 jun. 2020.

RONCA, Antônio Carlos Caruso; ESCOBAR, Virgínia Ferreira. Aula expositiva. In: Técnicas Pedagógicas: domesticação ou desafio à participação. 5 edição. Petrópolis: Vozes, 1988. 
SÁ, Pedro Franco de. Atividades para o ensino de Matemática no nível fundamental. Belém: EDUEPA, 2009.

SÁ, Pedro Franco de. Possibilidades do ensino de Matemática por atividades. Belém: SBEM-PA, 2019. Disponível em http://sinepem.sbempara.com.br/file/V7.pdf. Acesso em: 21 jun. 2020.

SOBREIRA, André Alves. O ensino de Matemática Financeira e aplicações. 2018. $450 \mathrm{f}$. Belém: Dissertação. (Mestrado Profissional em Ensino de Matemática) - Universidade do Estado do Pará, Belém, 2018. Disponível em:

http://educapes.capes.gov.br/handle/capes/559511. Acesso em: 21 jun. 2020.

SOBREIRA, André Alves; PEREIRA, Ducival Carvalho. Uma sequência didática para o Ensino de Matemática Financeira. 2018. 64 f. Belém: Produto educativo. (Mestrado Profissional em Ensino de Matemática) - Universidade do Estado do Pará, Belém, 2020. Disponível em:

https://educapes.capes.gov.br/bitstream/capes/569792/1/PRO_Andre\%20Alves\%20Sobreira.p df. Acesso em: 21 jun. 2020. 